\title{
The Right to Parent One's Biological Baby*
}

\author{
ANCA GHEAUS \\ Philosophy, Erasmus University, The Netherlands
}

\section{WHY PROBLEMATIC?}

$\mathbf{I}^{\mathrm{T}}$ $\mathrm{T}$ is generally accepted that individuals have a number of parenthood-related moral rights, such as the right to decide whether, with whom, when and how often to procreate, and to decide on many important aspects of how their children are raised. These moral rights have legal counterparts, often codified in national and international legal documents. One of them is the presumptive moral right of individuals to keep and raise their biological children. ${ }^{1}$ This right is undisputed, and legally protected, as long as parents meet certain criteria which deem them to be adequate parents. ${ }^{2}$ However, its philosophical justification is far from clear. It depends on answers to the questions: what makes parenting in general legitimate and how do individuals acquire the right to parent a particular baby?

The importance of these questions became particularly salient as the traditional conception of what is a child-and, implicitly, of parenting-lost its grip. The right to keep and raise one's biological baby is part of a bundle of various parenthood-related rights, grounded in a long philosophical tradition. Children have been conceptualised as unfinished human beings with interests of their own (including qua future adults) and, at the same time and somewhat contradictorily, as being their parents' property. ${ }^{3}$ The first feature of this traditional conception provided an answer to the question concerning the legitimacy of parenthood, the second to the question concerning the acquisition of parental rights with respect to particular babies. The understanding of children as incomplete adults, with interests of their own, originated in Aristotle and Locke. It generates legitimate paternalism - the idea that children need parents and that parenthood involves a

*I am grateful for helpful feedback to Daniel Engster, Sally Haslanger, Adina Preda, Ingrid Robeyns, Shlomi Segall, Adam Swift, Andrew Williams and Jurgen de Wispelaere. This research was funded by the Dutch National Science Foundation (NWO).

${ }^{1}$ I should add 'and adopted'. I leave adoption out for now, for the sake of simplicity, but I will briefly discuss it in the last section of the article, after I give my positive account of people's right to parent.

${ }^{2}$ Henceforth I use 'rights' without further specification to refer to moral rights.

${ }^{3}$ For this interpretation, see the editors' introduction to The Moral and Political Status of Children, ed. D. Archard and C. Macleod (Oxford: Oxford University Press, 2002), pp. 1-15. See also Robert Goodin, 'Responsibilities for children's well-being', No Time to Lose: The Wellbeing of Australia's Children, ed. S. Richardson and M. Prior (Carlton, Vic.: Melbourne University Press, 2005), pp. $60-82$. 
parental obligation, and right, to make decisions that promote children's wellbeing and guide children's development towards maturity. Aristotle conceived of a fathers' relation of ownership to his children as similar to a man's relation of ownership to his slave. ${ }^{4}$ Some classical liberals and libertarians proposed a less literal interpretation of children as their parents' property, representing them as extensions of their parents' labour ${ }^{5}$ or sense of self. ${ }^{6}$ If children are their parents' property—of some sort or another ${ }^{7}$ - this obviously means that parents have a right to raise their children themselves. Therefore, according to one understanding of children and parenthood, parenthood is legitimate because it is necessary for the well-being of children, and the people most entitled to function as parents of any particular child are those who procreated the child. Hence, the parental right to keep and raise one's biological baby.

The conception of children as unfinished adults endures ${ }^{8}$ and continues to ground many parenthood-related rights: as proto-adults, children need proper environments and guidance to ensure they will develop into socially competent and autonomous adults. But the philosophical and legal representation of children as their parents' property is now largely outdated. ${ }^{9}$ This poses a challenge to the traditional justification of the belief that biological parents have an automatic right to fulfil the role of parenthood. The right to keep one's biological baby must be discussed anew.

Recently, several philosophers have defended the fiduciary (child-centred) model of childrearing rights, justified in terms of children's interests. ${ }^{10}$ They argue that children, as intrinsically dependent beings, need continuous nurturing and protection from committed adults, that is, they need parents. Parents themselves need certain powers and freedoms to act on behalf of, and to protect their relationship with, children. The child-centred theory explains why children need

\footnotetext{
${ }^{4}$ Aristotle, 'Nicomachean ethics', The Complete Works of Aristotle, ed. J. Barnes (Princeton, NJ: Princeton University Press, 1984), 5. 6. 1134b.

${ }^{5}$ Robert Nozick, Anarchy, State and Utopia (Oxford: Blackwell, 1974), pp. 288-9, argues that John Locke's account of legitimate property acquisition by mixing one's labour in the creation of what is to be owned commits Locke to some sort of child ownership model.

${ }^{6}$ Robert Nozick, The Examined Life (New York: Simon \& Schuster, 1989), p. 28.

${ }^{7}$ Susan Moller Okin provides an analysis of the relationship between parents and children entailed by Nozick's libertarianism as being necessarily one of property. See Susan Moller Okin, Justice, Gender and the Family (New York: Basic Books, 1989).

${ }^{8}$ See, for example, the influential argument developed by Tamar Schapiro, 'What is a child?' Ethics, 109 (1999), 715-38.

${ }^{9}$ Okin's Gender, Justice and the Family was meant as a (radical) criticism to libertarian philosophy in general, and hence also to the private ownership over children model. For more recent critical work on this, see Daniel Engster, 'The place of parenting within a liberal theory of justice: the private parenting model, parental licenses, or public parental support?' Social Theory and Practice, 36 (2010), 233-62. However, some contemporary philosophers, such as a Hillel Steiner, believe that parents have an (encumbered) ownership right over their biological children. See Hillel Steiner, An Essay on Rights (Oxford: Blackwell, 1994), pp. 237-48. Moreover, the conception of children as private property is still influential in everyday parental practices. For this last point, see Hugh LaFollette, 'Licensing parents revisited', Journal of Applied Philosophy, 27 (2010), 327-43 at pp. 341-2.

${ }^{10}$ Samantha Brennan and Robert Noggle, 'The moral status of children: children's rights, parents' rights, and family justice', Social Theory and Practice 23 (1997), 1-25. Sarah Hannan and Richard Vernon, 'Parental rights: a role-based approach', Theory and Research in Education, 6 (2008), 173-89.
} 
parents, and why parenthood comes with specific rights, but it does not explain how people acquire the status of a parent in the first place. It is true that all children are born of particular human beings, but this need not mean that they should be parented by their biological parents. Arguably, some people make better parents than others, and sometimes there are individuals or couples who wish to parent and who would be better parents than the biological ones. If parenthood and parenthood-related rights are justified by appeal to children's interests, why not allocate babies, at birth, to those who would be the 'best' parents? One answer to this question can be found in various accounts of why it is indeed in children's interest to be raised by their biological parents. For example, David Velleman argued that knowledge of one's kin is important for one's well-being. But these positions seem highly speculative and, arguably, indebted to prevalent ideologies of the natural family. ${ }^{11}$ In this article I give a reason why adequate parents have a moral right to keep and raise the babies they have borne, based on the importance of one kind of biological tie. Unlike other current arguments grounded in biology ${ }^{12}$ my argument is ultimately justified by parents' own interests in keeping and raising their biological babies.

Arguments that do not ground parental rights exclusively in the interests of children, but also in adults' interest in parenting, are more promising as answers to the challenge of 'baby redistribution'. This parent-centred view sees parental rights as complementary, rather than opposed, to the fiduciary model..$^{13}$ Parent-centred views have been developed by Ferdinand Shoeman and then by Harry Brighouse and Adam Swift. ${ }^{14}$ Shoeman's position appears untenable, mostly because it fails to take children's interests seriously enough. ${ }^{15}$ Here I build on more recent work by Brighouse and Swift, to whose parent-centred account I am sympathetic.

\footnotetext{
${ }^{11}$ See: David Velleman, 'Family history', Philosophical Papers, 34 (2005), 357-78. For criticism, see Sally Haslanger, 'Family, ancestry and self: what is the moral significance of biological ties?' Adoption and Culture, 2 (2009), 91-122.

${ }^{12}$ Engster, 'The place of parenting within a liberal theory of justice', suggests that a child-centred argument for allowing parents to keep their biological babies is that otherwise pregnant women would put less effort into making sure their pregnancies go well. He also refers to some evidence that non-biological parents are more likely to abuse their children than biological ones.

${ }^{13}$ And some philosophers, such as Matthew Clayton, explicitly adopt a 'dual-interests' view of parental rights, which relies on both children's interests in being parented and adults' interest in parenting. See: Matthew Clayton, Justice and Legitimacy in Upbringing (New York: Oxford University Press, 2006).

${ }^{14}$ Ferdinand Shoeman, 'Rights of children, rights of parents and the moral basis of the family', Ethics, 91 (1980), 6-19. Harry Brighouse and Adam Swift, 'Parents' rights and the value of the family', Ethics, 117 (2006), 80-108.

${ }^{15}$ Hannan and Vernon, 'Parental rights'. Brighouse and Swift, 'Parents' rights and the value of the family', also criticise Shoeman for failing to account for the way in which people acquire parental rights. According to this criticism, Shoeman does show that, once parents and children are in an intimate relationship, the state is not permitted to interfere and disrupt it; but he does nothing to show why a redistribution of babies at birth is wrong. I disagree with this particular criticism of Shoeman because, as I argue in this article, at birth parents already have an intimate relationship with the baby they have borne. Moreover, if my interpretation of the Brighouse-Swift account is correct, it also fails to give an account of how an individual or couple acquires the right to parent a particular child.
} 
Brighouse and Swift argue against using parental competence to redistribute babies from adequate biological parents to the 'best' parents. They do this by developing an account of fundamental rights to raise children, grounded in parents' own interests and generated by the specific features of the parent-child relationship. These rights are called 'fundamental' to distinguish them from parental rights derived from children's interests, that is, from those generated by the fiduciary model. But Brighouse and Swift do not set out to provide an answer to the question of how individuals acquire the right to parent a particular baby, and their account does not provide an argument against all redistribution of babies away from their biological parents, but only against redistribution from adequate to 'better' parents. ${ }^{16}$ They agree that more argument is needed in order to show why parents have the right to keep their biological babies. More specifically, if the right to keep one's biological baby is to be grounded in parents' interests, it is necessary to show that people have a sufficiently strong interest in parenting their biological children.

In this article I defend three claims. First, I claim that the argument advanced by Brighouse and Swift does not rule out all redistribution of babies born to adequate parents. This is because it does not provide an answer to the question of how individuals acquire the right to parent a particular baby, and hence to the question of whether and why there is a right to keep one's biological children. Presumably, the 'better' parents have the same right to the specific good of parenting. This means that a fair decision about who should parent each individual baby may, in the absence of a right to keep one's biological children, require either that the 'best' parents be given priority or that a lottery should allocate babies randomly between all people who wish to parent and who would make at least adequate parents. Therefore, the Brighouse-Swift account alone will not diffuse the worry that superior parenting competence can, in some circumstances, be a relevant criterion for 'baby redistribution'. Their account of fundamental parental rights is incomplete.

Second, I show that in societies with entrenched histories of injustice there may be reasons of justice, other than fairness to all people who wish to parent, that warrant baby shuffling amongst all recent parents. These reasons would hold even if, in spite of my first claim, the Brighouse-Swift account succeeded in showing why babies should not be given to 'better' parents if their biological parents are adequate. This shows the importance of establishing how people acquire the right to parent a particular child, and specifically, whether there is a right to keep one's natural baby.

Third, I aim to supplement the Brighouse-Swift account of fundamental parental rights with an account of how adequate parents acquire the right to

${ }^{16}$ I often refer to 'better' or 'best' parents—which Brighouse and Swift manage to avoid—for the sake of simplicity. I use inverted commas to draw attention to the very problematic nature of establishing standards of excellence in parenthood, especially above the threshold of adequacy, and of identifying individuals who meet them. 
parent their biological babies. I advance two reasons which, taken together, show why one kind of biological parents, namely birth parents, have the moral right to keep their birth babies if they make at least adequate parents. Like Brighouse and Swift, I rely on an interest-based account of rights and I think there are parent-based interests to ground this right. The reasons are highly intuitive: given that babies come into the world through a gradual, sometimes complicated, approximately nine-month long gestation in their mothers' bodies, by the time of birth the birth parents will have already shouldered various burdens necessary to bring children into existence. On its own, this would not suffice to grant birth parents the right to keep their own baby-instead it would show that birth parents have the right to keep and raise one of the babies born at that time. But, in addition to the resources they invest in pregnancy, birth parents, or at least gestating mothers, are typically highly emotionally invested in the pregnancy. An intimate relationship with the future baby starts even before the baby is born, partly because birth parents devote significant resources to pregnancy and incur the many kinds of costs it entails. Thus, to shuffle babies between all people that are willing and able to parent would be unfair to birth parents and would destroy already formed parent-baby relationships. I assume that intimate relationships are intrinsically valuable for those who are involved in them and that the incipience of such relationships during most pregnancies is to some extent unavoidable, given the bodily connection between fetus and gestating mother. It would therefore be both undesirable and very difficult, if possible, to prevent the formation of parent-baby relationships during gestation.

The third point is, obviously, about one type of biological tie. It pertains only to the birth parents, that is, the gestating mother and her supportive partner, if she has one. Similarly, by 'biological baby' I mean 'birth baby'. Given the current possibilities of assisted reproduction, this is an important distinction. My argument has nothing to say about individuals who claim biological parenthood rights on the sole basis that they contributed sperm or ova. In the last sections I use 'birth parents' and 'bearing parents' interchangeably, to account for the fact that most biological parents are (still) bearing parents, without losing sight of the fact that gestation is the feature of biological parenthood which holds the water of the argument.

\section{IS ALLOCATION TO 'BETTER' PARENTS (ALWAYS) ILLEGITIMATE?}

One of the questions that Brighouse and Swift set out to answer is: 'If, for example, the state decided to redistribute children at, or soon after, birth, from what it deemed less suitable to what it deemed more suitable parents, would it be violating the rights of parents (as opposed to merely harming them or doing some wrong to the child)?"17 The hypothetical redistribution would be away from people who are either birth parents or adoptive parents.

\footnotetext{
${ }^{17}$ Brighouse and Swift, 'Parents' rights and the value of the family', p. 81.
} 
Their answer is positive, but qualified. The qualification consists in the condition that people ought to meet a minimum standard of parental adequacy in order to acquire and retain parental rights. Adequate parents must be able to protect their children's interests 'up to a fairly high threshold. ${ }^{18}$ People who would make adequate parents have limited, but fundamental, rights as parents. Many-perhaps most—adults have a strong interest in parenting in virtue of a few special characteristics of the parent-child relationship which, according to Brighouse and Swift, make it particularly valuable and, at the same time, morally unique. First, the relationship between parents and children is structurally unequal, determined as it is by children's intrinsic vulnerability. By contrast, vulnerability in relationships between adults is more reciprocal. Second, unlike parties in other relationships, children do not have the power to exit the relationship with their parents without putting themselves in serious jeopardy. Third, children love their parents in a uniquely spontaneous, unconditional and unreflective way. Finally, parents are in charge of their children's wellbeing and development to an extent to which people are not responsible for other individuals, with whom they stand in different types of relationships. The first two and the last features of the parent-child relationships generate the distinctive moral burdens of parenthood. According to Brighouse and Swift, meeting these burdens is valuable to parents, as part of a process of self-knowledge and personal development in which most people find unique satisfactions. The third feature points to a specific source of satisfaction of parenthood. In order to be able to successfully take on the burdens and enjoy the satisfaction that parenthood can bring, parents need the freedom to interact with their children in discretionary ways; their freedom ought, however, to be limited by the children's interests as well as by other desiderata, such as fairness. Parental rights protect this freedom.

The special characteristics of the parent-child relationship also make parenthood too valuable to be denied to people on the mere grounds that other people would make 'better' parents. The argument here seems to be that the losses suffered by dismissed parents are greater than the gains enjoyed by children with improved parents, if dismissed parents do not fall below a threshold of competence. As long as parents are adequate, they 'should not be left childless' in favour of those deemed to be better parents. Thus, the Brighouse-Swift account is meant to show that individuals' fundamental right to parent would make the allocation of babies to people deemed better parents a violation of parents' rights. Their argument, as they admit, does not show that the specific children that parents 'should be allowed to raise should be their own biological children'. ${ }^{19}$ In other words, Brighouse and Swift only give reason against a particular kind of

\footnotetext{
${ }^{18}$ Ibid.

${ }^{19}$ Ibid., p. 97.
} 
'baby redistribution'. But in this case, how strong are the implications of their account for the question of whether the parents have the right to keep their babies?

To start with, if successful, the Brighouse-Swift account shows why all individuals who wish to parent and are able to do so adequately have a fundamental right to parent in general, but it does not show why any individual has a right to parent any specific baby. As Brighouse and Swift themselves note, the characteristics which make the parent-child relationship morally valuable and unique do not depend on the existence of a biological connection between parent and child. This means that people who do not have biological children may have the same moral interest in parenthood as people who do have biological children. It follows that people without biological children have an equal fundamental right to parent in general if they can be at least adequate parents. Then why should these people have less opportunity than biological parents to enjoy the goods of parenting? If there are more potential adequate parents than babies to be parented (that is, if there is 'baby scarcity'), then there are two plausible possibilities for determining who should have the right to parent particular babies.

First possibility: if childless people who wish to parent have the same fundamental rights as biological parents to become parents in general, then there is at least one reason to 'redistribute' babies from people deemed less adequate parents to the 'better' parents. The reason is provided by children's important interest in having, all other things equal, better rather than less good parents. Children's interests in having better parents would then determine whose moral right to parenthood would be honoured. But this would contradict one conclusion reached by Brighouse and Swift, namely that 'no one who will do an adequately good job of raising a child should be prevented from being a parent'. ${ }^{20}$ In this case, their account is not sufficient to show why the interest in parenting 'impugns redistribution away from people who would be adequately good parents (though not as good as others). ${ }^{21}$

A situation warranting such redistribution might be described as one in which it is impossible to honour everybody's fundamental right to parent in general, and therefore moral considerations different from a fundamental right to parent in general should be used to decide who has the right to parent the particular babies in question. If all prospective adequate parents have the same fundamental right to parent in general, it is not clear what speaks against redistributing babies from the 'less good' to the 'better' parents, absent a reason to give priority to biological parents. A redistribution might be justified on reasons of parental competence without violating anybody's fundamental right to parent in general (since perhaps the people who do not get a chance to parent this time will get a chance

\footnotetext{
${ }^{20}$ Ibid.

${ }^{21}$ Ibid., p. 98.
} 
to parent in the future). It is plausible that who has the right to parent a particular baby should be the answer to an all-things-considered question.

Second possibility: perhaps a more egalitarian approach would suggest that, under conditions of scarcity, all people who would make at least adequate parents should be allowed to enter a baby-allocating lottery. Allocating the right to parent particular babies through a lottery would not violate the rights of adequate parents: even if some children would be likely to end up with 'better' parents than their biological parents, the redistribution would not be done in virtue of some people making 'better' parents, and no individual left childless would be denied parenthood for reasons of parental competence. Rather, in this case, the right to parent particular babies would be decided on grounds of fairness.

Irrespective of whether the allocation of babies amongst equally entitled individuals should be decided by appeal to parental competence-and implicitly to children's interests—or by appeal to fairness, some birth parents would be denied the opportunity to parent their birth children. Note that the extent of redistribution towards the 'better' parents need not be narrower if babies are allocated by lotteries rather than by considerations of parental adequacy.

At this point, one may worry whether the question concerning the redistribution of children to better parents contains an ambiguity. Brighouse and Swift do not employ the distinction, essential for understanding their question, between 'birth parent' and 'social parent'. ${ }^{22}$ The first can only be descriptive: it refers to the individual to whom a particular baby was born. The second can be socially normative, when it refers to the individual who actually plays the parenting role of a particular baby, whether or not she or he has a moral right to do so; or it can be fully normative, when it refers to a legitimate parent, that is to the individual who has the moral right to parent that particular baby. In the question raised by Brighouse and Swift, the first and third mention of 'parents' (those deemed less suitable) refers to people who are both birth and social parents in the socially normative way and, potentially, legitimate social parents; the second mention of 'parents' (those deemed more suitable) refers to people who are, potentially, legitimate social parents. In real world societies, birth parents usually already function as social parents, which suggests that there is already a reason against operating a baby redistribution away from them.

One such reason, I argue, is easily at hand: presumably, there must exist at least an incipient intimate relationship between babies and their birth or adoptive parent who functions as their social parent. But the explicit aim of Brighouse and Swift's argument is not merely to show why, once a parent-baby relationship exists, third parties should not end it for the sake of giving the baby a 'better' 
social parent-that much, they suggest, we can take for granted. ${ }^{23}$ Rather, they want to account for the fundamental right to parent babies in general, without helping themselves either to arguments based on biological ties or on already existing relationships with babies. The question, then, is whether establishing a fundamental right to parent in general is enough to show that social parents in the socially normative sense have the right to parent the particular babies they happen to be parenting - that is, whether they are the legitimate social parents.

The question raised by Brighouse and Swift seems to assume a certain initial allocation of babies, that is, an already functioning relationship of social parenthood at birth. The question, then, is how individuals become legitimate social parents. If one factors out biological parenthood, including the intimate relationship which often exists between babies and birth parents, it is difficult to see what speaks in favour of granting the right to parent the particular babies to their adequate birth or adoptive parents rather than to 'better' parents. I hope to show that, if one does not factor out these considerations, one can see why birth parents have parental-interest based right to keep their babies, which is more than Brighouse and Swift aim to do.

This is not a criticism of Brighouse and Swift's account of why people have a fundamental right to parent in general, which I find convincing. Rather, it is meant to indicate the limits of their account, and the insufficient support this account gives to a right to keep one's biological baby against redistribution to 'better' parents, as long as it is not supplemented by an account of what singles out birth, or already designated adoptive, parents.

\section{THE INTUITIVE BASIS OF FUNDAMENTAL PARENTHOOD RIGHTS}

Here comes, however, a more serious worry. Does the interest in parenting necessarily amount to a fundamental right to parent? More specifically, can a right to parent in general be derived from the said interest?

One type of criticism to the Brighouse-Swift account was developed by Sarah Hannan and Richard Vernon, who accept both that individuals have strong moral interests in parenting, and that there are parents' rights which include a general right to become a parent. But they deny that parents' rights are indeed grounded in parents' interests- that is, they deny that there are any fundamental rights to parent. ${ }^{24}$ Hannan and Vernon believe that the Brighouse-Swift account of the moral interest in parenting does show how people acquire rights which prevent babies' redistribution away from biological parents. By contrast, I believe

\footnotetext{
${ }^{23}$ As is clear in their discussion of Shoeman, whose argument they find insufficient precisely because it does not account for the way in which the parent in question acquired the right to parent the baby in question. They hope their argument will address the issue missed by Shoeman's argument.

${ }^{24}$ See Hannan and Vernon, 'Parental rights'. Instead, they argue, parental rights should be ultimately grounded in children's interests; if we allow parental interests to ground parental rights we run too high a risk of legitimising practices which contravene the children's wellbeing.
} 
the Brighouse-Swift account provides a convincing account, in terms of fundamental parents' rights, for right to parent in general. But it only shows that, once a relationship between parents and children is established, this right is reason enough to prevent babies' redistribution, and not why people have any right to keep their birth babies in the first place..$^{25}$

Whether a fundamental right to parent in general can be derived from the moral interest in parenthood turns on whether one thinks (as I do) that a fundamental right may depend on empirical facts about the world inhabited by the rights bearers. In this section I propose and discuss a speculative claim: the fundamental right to parent, defended by Brighouse and Swift, draws its intuitive appeal from more empirical facts about parenthood than they discuss. These facts are true about the world as we know it; absent these facts, the strong interest in parenting that Brighouse and Swift identify would not have the force of a right.

My speculative claim is plausible given the understanding of rights adopted by Brighouse and Swift themselves. They take an interests-based approach to rights, where rights are 'moral constructs designed to protect interests, which are the truly fundamental moral considerations. ${ }^{26}$ In turn, people's interest in parenting is grounded in the allegedly unique empirical features of the relationship between parents and children. Moreover, parents' rights are said to be fundamental only in the sense that they derive from parents' (rather than from children's) interests, as opposed to being fundamental in the intuitive sense in which the right to life is fundamental. The crucial question then seems to be whether a fundamental right can be derived from morally important interests independently of other circumstances of the world. Brighouse and Swift note that parents' fundamental rights need not be 'fundamental' as in 'fundamentally important'-but simply as in 'being owed to persons and grounded in the benefits they bring to the right holders alone'. Fundamental parents' rights, they note, might be more like a right to vote than like a right to life; both a right to vote and a right to life can be justified by reference to the interests of the right-holder only, but the second is obviously more important than the first. But, I assume, it is plausible to explain the difference in importance between these two rights through the fact that a right to life is independent of particular social circumstances, whereas a right to vote acquires both its meaning and its normative justification in particular social and institutional settings.

In this case, the justification of a fundamental right to parent must take into account a rich constellation of facts about procreation and parenting. The modification of one or several such facts can cast doubt on the existence of the right. I believe that, in the case of a right to parent, these facts concern the gradual nature of what we consider good parenting, the epistemic and moral barriers to

${ }^{25} \mathrm{I}$ also think, unlike Hannan and Vernon, that the account offered by Brighouse and Swift succeeds in showing that people's moral interest in parenting grounds very limited fundamental parental rights concerning childrearing.

${ }^{26}$ Brighouse and Swift, 'Parents' rights and the value of the family', p. 87 n. 13. 
establishing where on the scale of good parenting individual parents belong, the number of available babies and parents, and the way in which babies come into the world. The last feature, I will argue eventually, is the most important.

Imagine the following counterfactual situation, where (a)-(d) represent permanent features of the world:

(a) Good parenting (that is, above the adequacy threshold) is not a matter of degree. Rather, all individuals who would not make bad parents would make either adequate or excellent parents. This denies the gradual nature of good parenting, which is a fact about the world as we know it.

(b) It is possible to find out which individual is in what category, because we have clear, unchanging and operational definitions of adequate and of excellent parenting, and we can apply the relevant tests without putting people at the risk of social stigmatisation or intruding on their privacy in objectionable ways. ${ }^{27}$ This denies the real-world fact that there are epistemic and moral barriers to ranking parents.

(c) There is an equal number of people who want children and would make excellent parents but who are unable to conceive-call them 'the excellent infertile potential parents' - and of people who want children, would make adequate parents and who can conceive (call them 'the adequate fertile potential parents'). Suppose, moreover, that people from both groups have an equally intense desire to raise the babies, and would derive the same benefit from parenting. People who would make inadequate parents are also infertile.

(d) Babies do not come into the world through a process which takes approximately nine months, during which they develop in their mother's womb. Instead, ova and sperm are collected from the fertile couples and from fertilisation onwards the future babies are grown in medically designed and controlled environments. Each couple is able to conceive only once during their lifetime. Thus, there is a continuous scarcity of babies. As a matter of custom and legal provisions, when babies become viable independently of medical technology, they are taken from the hospital, and are then parented, by their biological parents.

If (a)-(d) were permanent features of the world, the very meaning of 'biological parent' would be much thinner than it is in the world as we know it: it would be exhausted by the genetic connection. Under such circumstances it seems very plausible that, in spite of the existing practices of the society described above, the state ought to at least allow the excellent infertile potential parents to parent the babies, which means that the adequate fertile parents cannot have a

\footnotetext{
${ }^{27}$ For a reason why stigmatisation is so bad that it should sometimes prevent us to from defining people's rights in ways which invite stigmatisation (for example, defining rights to welfare provisions by appeal to special need), see Jonathan Wolff, 'Fairness, respect and the egalitarian ethos', Philosophy and Public Affairs, 27 (1998), 97-122.
} 
right to keep their biological babies. The duty would be amply justified by the wellbeing of children and the social utility better promoted by excellent, rather than adequate, parenting. By assumption, all potential (adequate and excellent) parents have an equal interest in parenting. Genetic reasons ${ }^{28}$ aside, there would be no reason to give more weight to the fertile than to the infertile, and if we can (since (b) holds) benefit all children significantly (since (a) holds), then there is a strong case for granting the excellent infertile the right to parent. There would be no discrimination, because all the adequate fertile would lose their children to the excellent infertile. ${ }^{29}$

The only reason to resist granting the excellent infertile prospective parents the right to parent the babies would be the strong moral interest in parenting, which is equally held by the adequate infertile and the excellent fertile prospective parents. Indeed, if (d) alone was true there would be good grounds for allocating babies through a lottery which, as already argued, is compatible with the recognition of a fundamental right to parent. But if (a) and (b) are true as well, there is a choice between three different scenarios:

(i) Trumping fundamental right to parent. We could acknowledge that both the excellent infertile and the adequate fertile prospective parents have a fundamental right to parent in general, and judge this right to be more important than children's interest in having excellent parents, plus social utility. The adequate decision-making procedure would be a lottery, as a fair way to allocate babies and to establish rights to parent individual babies.

(ii) Trumped fundamental right to parent. We could acknowledge that both the excellent infertile and the adequate fertile prospective parents have a fundamental right to parent in general but judge this right to be less important than children's interest in having excellent parents, plus social utility. Then the excellent infertile potential parents would be able to exercise the right to parent specific babies, while the adequate fertile potential parents would never exercise their right to parent in general. But, in this case, it is unclear why we should acknowledge a right to parent in general at all, given an understanding of rights as moral constructs meant to protect important interests. This scenario is incoherent, which leaves one more possibility.

(iii) No fundamental right to parent. We could deny that a strong moral interest in parenting actually amounts to a fundamental right to parent in general, given its structural incompatibility with children's interest in having excellent, rather than merely adequate, parents, plus social utility.

\footnotetext{
${ }^{28}$ Which neither Brighouse and Swift nor I regard as sufficiently convincing. But some people, including contemporary libertarians (such as Steiner, An Essay on Rights), who believe that we own our own genetic material, are likely to think otherwise. Note that, if one of these people argued that adequate fertile people have the right to parent babies, they will have to justify this as a right to keep one's baby because it is a biological child, not as a right to keep one's baby because one is an adequate parent and has a strong moral interest in parenting.

${ }^{29}$ There might, of course be a practical problem with motivating the adequate infertile parents to contribute sperm and ova towards creating children.
} 
The interesting choice is then between (i) and (iii). The only reason which speaks in favour of adopting (i) over (iii) is fairness towards prospective parents, which requires the protection of adults' equal chances to realise their strong interest in parenthood. Only the acknowledgment of a fundamental right to parent could effectively protect equal chances to realise this interest. The problem is that, if a fundamental right to parent in general is acknowledged out of a sense of fairness, the same value-fairness-will necessarily be violated when it comes to children's wellbeing: in trumping fundamental right to parent some children would end up with excellent parents, while others only with adequate parents, while in no fundamental right to parent they would fare equally well in terms of expected parental care. Therefore, while allocating babies through a lottery may be fair towards potential parents, it is unfair towards the children. If the facts of the world make it impossible to be fair both towards prospective parents and towards children, then an all-things-considered judgment should tip the balance in the direction indicated by the other values at stake-in this case, towards no fundamental right to parent.

Given the general caution with which they argue for the existence, and limits, of fundamental parents' rights within a wider context of other people's interests, ${ }^{30}$ I do not see how Brighouse and Swift could favour the trumping right to parent scenario. The no right to parent scenario is more convincing.

It is then likely that the account of a fundamental right to parent in general draws its intuitive appeal from those features of real world parenting which are contradicted by (a)-(d). Because in the real world there is no enduring baby scarcity, and, as far as we know, no correlation between excellent parenting and fertility, the prima facie reason for a redistribution of babies according to parental competence is much weaker than in the above-sketched counterfactual world. And, because in the real world there are serious epistemic and moral barriers to establishing hierarchical standards of parental excellence above a certain threshold, even if there was a strong prima facie reason in favour of baby redistribution, it would most likely be morally wrong to carry it out. Given the empirical features of the real world we do not even know what it would mean to benefit children by redistributing them from adequate to excellent parents-since the standards of parental excellence are essentially contested norms. Therefore, given the actual features of the world, it is plausible to think that the interest in parenting that most adults have amounts to something as strong as a moral right to parent in general.

But one feature of how children actually come into the world, pregnancy, can also ground a fundamental right of adequate parents to keep the babies that result from their own pregnancies. To emphasise the importance of a fundamental moral right to keep one's birth baby, I briefly indicate in the next

\footnotetext{
${ }^{30}$ That is, children's own interests and rights qua children, and everybody's interest in a fair society. For the second type of interest, see Harry Brighouse and Adam Swift, 'Legitimate parental partiality', Philosophy and Public Affairs, 37 (2009), 43-80.
} 
section real-world reasons (additional to fairness towards childless people who would make adequate parents) to shuffle babies between prospective parents.

\section{WHY SHUFFLE BABIES AMONGST ADEQUATE PARENTS?}

Even if the Brighouse-Swift account successfully showed that adequate parents have fundamental rights against a competence-based redistribution of babies, it does not claim to give a reason for banning all redistribution of babies: for example, it is silent on the question of whether to shuffle the newly-born between all recent, adequate biological parents. Admittedly this limitation is problematic only if there are good reasons for redistribution in the first place: if there are no such reasons, the mere desire of people to parent their biological children may be a sufficient argument against redistribution. But sometimes there are moral reasons of fairness for shuffling babies directly after birth between birth parents. The new distribution of babies would satisfy people's fundamental right to parent in general as much as the initial distribution.

Some societies have entrenched histories of racial discrimination. In the United States, for example, racial history determines very unequal opportunities for black and white people to lead materially decent lives (including proper housing and food), to achieve social status, to have access to education and good health, and to overcome social marginalisation. The legacy of racial discrimination seems very difficult to undo, despite decades of affirmative action and positive discrimination. Although some individuals who belong to the historically discriminated race manage to attain socially advantaged positions, the majority of their racial fellows remain disadvantaged. Given the way in which social, economic and cultural advantages are reproduced within families, shuffling all babies born in the US between all the new parents at birth would advance social justice by undermining the connection between advantage and race. ${ }^{31}$ In the short term this measure would break the connection between race and unequal opportunities; being born black or white would no longer correlate (very strongly) with lower or higher undeserved opportunities. In the long term, this measure might help eliminate the social segregation between a poorer, less educated, less healthy, less respected race, largely dwelling in undesirable neighbourhoods and undertaking undesirable jobs; and a wealthier, more educated, healthier, more respected race, generally living in more attractive neighbourhoods and employed in more attractive jobs.

\footnotetext{
${ }^{31}$ Hawley Fogg-Davis, 'Racial randomization: imagining nondiscrimination in adoption', Adoption Matters, ed. S. Haslanger and C. Witt (Ithaca, NY: Cornell University Press, 2005), pp. 247-264, argues that racial randomisation in the adoption of babies in the USA would fight racism by advancing trans-racial adoption. This would stimulate critical thinking about race and challenge the stereotypes about race and inter-racial care-that is, the stereotype that black people are always in the position of providing care to white people.
} 
Other societies do particularly badly with respect to gender fairness. In China and India, for example, baby girls have historically been less valued than baby boys, for a variety of reasons having to do with structurally sexist social norms, customs and institutions. Against this background, the recent advancement of medical technology led to an increase in abortions of female fetuses. In turn, this practice perpetuates gender injustice. ${ }^{32}$ Thus, being conceived female entails, in these countries, a higher probability of being aborted. Given that there are also legitimate-including medical-reasons to screen the sex of fetuses, it may be undesirable to ban this practice. In China or India, the shuffling of all babies, at birth, between all the new parents, would provide a welcome disincentive to sexist practices of gender selection: if those who do not give birth to a baby do not enter the baby allocation lottery, then only people who would rather be childless than have a baby girl would continue to abort based on the sex of their fetus.

In the absence of a right to keep and raise one's biological baby, baby shuffling between all adequate recent parents would be legitimate, in certain social circumstances, for its desirable outcome of improving social fairness. In the next section I argue that some features of pregnancy provide good grounds for a fundamental right to keep one's biological baby, and that this right accrues to all adequate parents.

\section{THE IMPORTANCE OF PREGNANCY}

There are two general features of real-world pregnancies that speak in favour of adequate parents' moral right to keep their birth babies. First, pregnancies involve a variety of costs-physical, psychological, social and financial. Most of these costs can only be shouldered by pregnant women and, to some extent, their supportive partner. Second, during pregnancy many-perhaps most-expectant parents form a poignantly embodied, but also emotional, intimate relationship with their fetus. The two features are related, because this relationship is fostered by bearing parents' willingness to take on the costs of pregnancy and by their actual experience of its burdens. ${ }^{33}$ These two features of pregnancy can, given a fundamental right to parent in general, ground a parent-interest based right to keep one's birth baby.

\footnotetext{
${ }^{32}$ For a recent analysis of the scale of sex-selective abortion and the ways in which it perpetrates and perpetuates gender injustice, see Anon., 'The worldwide war on baby girls', The Economist, 4 March 2010.

${ }^{33} \mathrm{~A}$ strictly physicalist approach will say it results from oxytocin, a substance considered responsible for bonding and which is secreted during pregnancy. Whether one takes the phenomenological or the physicalist approach to analysing bonding during pregnancy might make a normative difference, but not in this context. A physicalist might argue, for example, that we should use oxytocin to help foster the emotional relationship between non-birth parents and babies. But this would not affect the present argument, which says that, one way or another, pregnancy itself fosters this relationship and hence taking babies away from their birth parents is morally wrong.
} 
Work on the phenomenology of pregnancy is very helpful for understanding both the numerous costs that pregnancy involves and the mechanisms through which it helps to create an incipient intimate relationship between the fetus and the pregnant mother and her partner, if the latter is sufficiently involved. In exploring these claims, I rely on work done by several feminists and I refer, in particular, to Amy Mullin's Reconceiving Pregnancy and Childcare.

The costs of pregnancy are varied: physical, emotional, social and financial. They consist in the actual pain of childbearing and childbirth, in pregnant women's reduced autonomy, in the health risks women take in order to carry their babies, in the worries about the mother's and the baby's health, and in the daunting risk of miscarriage.

The physical burdens of pregnancy have a significant effect on many pregnant women's ability to carry on with life as usual: 'Fatigue, high blood pressure, excessive water retention in one's hands and feet, nausea and vomiting, an inability to carry heavy objects, and other common symptoms of pregnancy do involve suffering and affect a pregnant woman's ability to carry out her daily tasks, whether in paid employment, domestic work, childcare or interactions with friends and family, regardless of how accommodating her environment may be. ${ }^{34}$ Some of the most important burdens of pregnancy result from the extent and pace of change, ${ }^{35}$ undergone by all pregnant women, which often contributes to a distinctive sense of losing control over one's life and a diminished ability to pursue other projects and interests during pregnancy as well as during recovery from childbirth. As Mullin notes, 'at no other time will an otherwise healthy adult undergo such widespread, rapid and undesired change in the shape and size of her body, in the way she moves, eats and sleeps. ${ }^{36}$

Many pregnant women also pay behavioural costs, limiting what they can eat and drink, the recreational drugs they can take and the sports and other physical activities which they can pursue. There are social costs to pay, such as patronising and uninvited familiarity: pregnant women are often 'told that nothing they can do could be more important than their job of bringing a child to life. ${ }^{37}$ Generally, pregnancy alters the expecting parents' relationships with their immediate family, friends, co-workers and, when the pregnancy is visible, even with strangers, in uncontrollable ways. Arguably, not all these changes count as costs, since in some cases pregnant women develop or strengthen welcomed relationships, based, for instance, on complicity, with other parents. But many of the changes are

${ }^{34}$ Amy Mullin, Reconceiving Pregnancy and Childcare: Ethics, Experience and Reproductive Labor (Cambridge: Cambridge University Press, 2005), p. 64.

${ }^{35}$ Mullin's Reconceiving Pregnancy and Childcare gives a very vivid sense of the many physical changes undergone by pregnant women: 'in visual acuity, pigment of her skin, the onset of rashes, nausea, heartburn, raised blood pressure, increased congestion, difficulty catching her breath, swollen hands and feet'. (Reconceiving Pregnancy and Childcare, p. 39.) Many of these are relatively minor, but together they can entail significant pain and disruption of one's normal life.

${ }^{36}$ Mullin, Reconceiving Pregnancy and Childcare, p. 67.

${ }^{37}$ Mullin, Reconceiving Pregnancy and Childcare, p. 40. 
undesirable and, importantly for the present argument, many of the desirable changes are based on the assumption that the pregnant women or parents will carry on parenting their birth baby. Moreover, the costs of pregnancy would actually be higher if bearing parents would not know whether they will be allowed to keep their birth baby. A frequent consolation given to pregnant women is that becoming a parent 'is worth all the trouble and pain'.

Finally, expecting parents have to shoulder specific emotional burdens such as fear of miscarriage and the anxiety of deciding whether to continue a pregnancy with significant health risks. A pregnant woman 'needs to come to terms with her welcoming of a creature who is already transforming her body, her social interactions, and her habits, who will always radically transform her life and about whom she knows virtually nothing. ${ }^{38}$ While they cannot share all these costs, involved partners typically can and do share many of them. They often are the main source of emotional, practical and financial support of their pregnant partner: they can accompany her on medical visits and support her during childbirth, share and try to soothe her worries, relieve her of some of her regular work and serve as an often-needed interface between her and the insufficiently accommodating outer world. Some, but not all, the costs of pregnancy can be socially prevented or mitigated. I elaborate on this point in the last section.

Pregnancy often involves specific benefits as well as costs. However, the benefits and joys of pregnancy do not cancel out the costs, and do not turn pregnancy into an intrinsically desirable experience. Certain benefits of pregnancy, such as the increased attention and care that pregnant women often receive, are meant to alleviate its costs: if pregnancy did not involve specific costs, these benefits would not exist either (in this respect, pregnancy is similar to illness and disability). Other benefits of pregnancy, such as the joyous anticipation of the baby, are only valuable given the assumption that one carries a baby one will keep and raise. Importantly, the most salient positive aspects of pregnancy are conditional on expecting that, at the end of one's pregnancy, one will become a parent. If, contrary to the claims I advance in this section, pregnancy turned out to be intrinsically valuable, or if the benefits of pregnancy outweighed its burdens without being parasitic on an expectation that birth parents will have the right to keep their babies, then one pillar of my argument for a right to keep one's birth baby would disappear.

Certain experiences of pregnancy, such as fragmented sleep and disrupted life patterns, may, precisely due to their hardship, prepare bearing parents to better care for their babies. Some authors think that pregnancy helps prepare mothers-and, when they are closely involved with pregnancy, their partners-to be ready for the major changes brought about by childrearing. ${ }^{39}$ If this is correct, it means that, other things equal, birth parents are more prepared to take care of

${ }^{38}$ Mullin, Reconceiving Pregnancy and Childcare, p. 43.

${ }^{39}$ Louise Levesque-Lopman, 'Decision and experience: a phenomenological analysis of pregnancy and childbirth', Human Studies, 6 (1983), 247-277. 
a baby and so that the child has an interest in being raised by somebody who is also a birth parent. The burdens of pregnancy then generate a child-based reason for allocating the right to parent particular babies, alongside a parental interest in raising one's birth child.

If all adequate prospective parents have a fundamental right to parent in general, but there is no right to keep one's birth child, then there is a prima facie reason to consider a baby-allocating lottery that would give all eligible adults who wish to parent an equal chance to do so. But, since pregnant women and their partners pay the various costs of pregnancy, there is good reason to give priority to these adults' claims to parenting the particular baby they have borne.

There is a certain similarity between justifying a fundamental parental right by appeal to the costs of pregnancy and the libertarian argument according to which parents have some kind of ownership over children because children result from their parents' labour. ${ }^{40}$ However, I do not argue that the costs of pregnancy, including the efforts it requires, entail anything as strong as ownership rights.

The argument from the costs of pregnancy provides some justification for a fundamental parental right to keep one's birth baby, but it may perhaps be overridden by other reasons-such as considerations of race or gender fairness. ${ }^{41}$ Appeal to the costs of pregnancy alone cannot exclude legitimate baby shuffling between all bearing parents: the burdens of pregnancy entitle potentially adequate parents, who just gave birth, to parent a baby, but not necessarily the baby they gave birth to. A second feature of pregnancy-the fact that it facilitates the creation of an intimate relationship between the bearing parents and the future baby-does the remaining theoretical work.

The two features of pregnancy-its significant costs and its facilitation of an intimate relationship with the future baby-are closely related. Because children come into existence through gestation, pregnant women and their supporting partners have to invest a significant amount of resources into having birth children. This is often a conscious, intentional process, akin to other projects in which people engage: it contains much anticipation and planning, thinking and hoping, imagination and projection. Through their bodily connection with the baby and their various psychological investments, expecting parents normally build a relationship with their future baby, which is sometimes highly emotional and already quite developed at birth. Bearing parents and their newborns already share a common history including numerous embodied common experiences ('you kicked me on the 1st of March', 'you made me worry', 'you made me so happy'). The fact that the body plays such a central part in pregnancy makes pregnancy a uniquely privileged context for developing a bond that is both physical and imaginative with the future child. Caroline Whitbeck has gone so far as to argue that people's affection towards their own children, often explained by

\footnotetext{
${ }^{40}$ See for instance: Steiner, An Essay on Rights.

${ }^{41}$ Since, as I noted already, the question of who should have the right to parent a particular child has to be an answer to an all-things-considered question.
} 
reference to a maternal/parental 'instinct', is actually rooted in bodily experiences: 'parental affection or attachment is influenced by experience, and this experience is not confined to socialization experience but includes, in a large measure, bodily experiences that are the same cross-culturally; i.e. all women have special bodily experiences that are likely to enhance those feelings, attitudes and fantasies, which induce people to generally care for their infants. ${ }^{42}$ These experiences include pregnancy, labour, childbirth and postpartum recovery, which are unique to the bearing mother. Whitbeck concludes that, although the maternal 'instinct' is itself a myth, biology-through embodied experience-plays a very important role in creating a bound between newborns and their mothers. This argument might soon be verifiable, when enough people exist whose bearing mothers are different from their genetic mothers. If this is true, then biology turns out to play an important role in parent-children relationships thanks to the biological processes of parenthood, independent of genetic connections.

Like in the case of paying the costs of pregnancy, pregnant women's supporting parents are capable of being direct participants in the process of creating a relationship with the baby during pregnancy. With the help of medical technology they can see the fetus and hear its heartbeat as early as the bearing mother; during the last stages of pregnancy they can feel the baby, talk to it and be heard by it. Just like the mother, they can experience the fears, hopes and fantasies triggered by the growing fetus.

The phenomenology of pregnancy does not show that all pregnancies generate intimate relationships between bearing parents and their newborns. It only shows that pregnancy can, and is likely to, lead to bonding; the likelihood is very significant, since bonding can happen even if the pregnant woman knows she will not be permitted to keep the baby-as we know from cases of surrogate mothers who have developed a strong attachment to their unborn, and then newborn, baby. Bonding during pregnancy provides a very solid reason for thinking that redistributing babies would likely destroy already existing intimate relationships between newborns and their bearing parents.

The fact that the relationship with one's future child starts during pregnancy provides the missing step in the justification of a fundamental parental right to keep and raise one's birth baby and the answer to the question of how to determine fundamental moral rights to parent particular babies. Other defenders of fundamental parental rights-most importantly, Shoeman ${ }^{43}$ - have argued that it is impermissible to disrupt already established intimate relationships between birth parents and children, for reasons of both parents' and children's welfare. But no reason was provided for why such relationships are permitted to develop

${ }^{42}$ Caroline Whitbeck, 'The maternal instinct', Mothering: Essays in Feminist Theory, ed. J. Trebilcot (Totowa, NJ: Rowman \& Allanheld, 1984), pp. 185-198 at p. 191.

${ }^{43}$ Shoeman, 'Rights of children, rights of parents and the moral basis of the family'. See also the discussion of this argument in Brighouse and Swift, 'Parents' rights and the value of the family'. 
in the first place if better parents are available. If the same process which brings babies into the world also generates their first intimate relationships adults, then relationships between birth parents and their babies need no justification: they are already there from the beginning. Adding the perspective of the baby, who also bonds with its mother whose voice, heartbeat, and so on it can recognise during the last phase of gestation, give additional, child-centred justification, to the right to keep one's birth baby.

In conclusion, the particular way in which we come into existence is essential for determining who has the right to rear us. If we all came into the world in laboratories, created by scientists, there would be little reason for granting a right to rear $\mathrm{us}^{44}$ to the people who provided the genetic material. Indeed, I argued there are reasons of fairness for redistributing babies between all potential adequate parents and, in certain social contexts a 'baby shuffling' would help tackle historical and deeply entrenched associations between race or gender and advantage.

To answer this challenge, I offered an account of how people acquire the right to parent a particular baby. One element of such an account is provided by the existence of a parental right to keep one's birth baby. If, at the moment of birth, adequate bearing parents have already paid significant costs for becoming parents, and in the process have developed an incipient intimate relationship with the baby, then they are more entitled than other prospective parents to parent the baby they have borne. This difference between adequate bearing parents and other adequate prospective parents can provide the necessary justification for translating the fundamental right to be a parent in general into a right that birth parents have to parent their birth baby.

\section{SOCIAL AND POLITICAL IMPLICATIONS}

Before ending, let me point out some of the social and political implications of this argument. First, social arrangements and the attitudes of non-pregnant people towards pregnant women and their partners can and do impact significantly on the magnitude of the costs involved by pregnancies. The most salient social arrangements which determine the burdens of expecting couples include: their living conditions, adequate nutrition, the level of medical care they receive and the way it is delivered, the flexibility or lack of flexibility in their working conditions, and the adaptation of physical spaces to allow expecting couples to pursue their interests and pleasures as usual. Similarly, caring and respectful, non-judgmental and non-intrusive attitudes of friends, family, strangers and medical personnel can ease the burdens of pregnancy. There are limits to the possible socialisation of the burdens of pregnancy. Better life

\footnotetext{
${ }^{44}$ Although some philosophers believe we have property in our genetic material. See, for example: Steiner, An Essay on Rights.
} 
conditions can ease the physical and psychological costs of pregnancy, but they cannot prevent the sometimes considerable pains of pregnancy. The advancement of prenatal medicine diminishes the health risks of pregnancies and alleviates some of its pains and worries; certainly, in the past pregnancy involved much higher levels of reasonable fear than it does now. In the past, pregnant women and those who loved them knew that any pregnancy could end in death or serious impairment; nowadays, in developed countries, these risks are considerably lower. At the same time however, the increased medicalisation of pregnancyaimed at prevention or early detection of medical problems-is itself a new source of worries and emotional distress: ${ }^{45}$ increased knowledge and control of our bodies comes at a price. Hence, there seems to be a trade off between the reasonable worries which accompany low levels of medical monitoring and intervention, and the worries, equally reasonable, triggered by increased knowledge of the numerous ways in which a pregnancy can go wrong. This is an example of how lowering some of the pregnancy costs for pregnant women create, for the same women, new costs. Then, there are obvious economic limits to the adaptation of working places and public spaces to meet the specific needs of pregnant women to the level that would be necessary for them to continue to pursue their pleasures and projects as before pregnancy. Finally, there is a fine line between wanted and unwanted attention, for which there are no quick and fast rules. It is likely that even the most respectful, sensitive and well-meaning friends, family members and strangers would occasionally fail to identify the line.

Therefore, no amount of social or individual accommodation and support can eliminate all the pain, unwanted rapid changes, worries and other difficult emotions evoked by incipient parenthood, and many of the impairments entailed by pregnancy, labour and childbirth. Pregnant women, and, to a lesser extent, their involved partners, will always have to pay these costs themselves.

Second, there are of course cases of pregnancies which do not involve bonding with the future baby and there are cases when there is no incipient intimate relationship between birth parents and newborns. It follows from my argument that these parents do not have a fundamental moral right to parent the particular baby they have borne. ${ }^{46}$ This is not an embarrassment for my argument. Because the existence of an intimate relationship between birth parents and newborns is the rule rather than the exception, it can, I believe, justify a legal right to keep one's birth baby. The occasional absence of the moral right will not nullify the legal right. Given the epistemic and moral barriers to finding out who is an adequate parent, and because children might be better off if they are not removed from their less-than-adequate parents, the absence of the moral right to parent in

\footnotetext{
${ }^{45}$ It is also a threat to pregnant women's autonomy, as the feminist critical literature on the medicalisation of pregnancy shows. See, for example: Ann Oakley, The Captured Womb: A History of The Medical Care of Pregnant Women (Oxford: Blackwell, 1984).

${ }^{46} \mathrm{But}$ if there is significant bonding with the mother from the baby's perspective, this may ground a parental right to keep and raise that baby based on the child's interest.
} 
general will not necessarily justify the forced removal of the child from her current family. Similarly, given epistemic and moral barriers to finding out whether there is an incipient intimate relationship between the birth parents and newborns, and given additional, child-centred, considerations, the absence of a moral right to parent one's birth child will not justify forced removal of children from their birth parents.

Third, in spite of some worries, ${ }^{47}$ recognising the moral relevance of prenatal bonding does not imply that adoption is always a 'second best' form of parenting. Just as pregnant women's partners can carry many of the costs of pregnancy and start an intimate relationship with the future baby, adopting parents can do the same. ${ }^{48}$ Indeed, prospective parents may start to create an emotional connection with the baby even before birth, for example by learning about the baby's family history, getting information about how the pregnancy goes, accompanying the pregnant woman or couple to medical checks and watching ultrasounds, talking to the baby while in its mother's womb, and witnessing the birth. When prospective adequate adopting parents have already participated in some of the costs of a particular pregnancy, and have already become emotionally involved in the life of the future baby, they should, other things being equal, have legal priority in parenting that particular baby even if better adoptive parents exist.

My argument also provides a relatively weak and certainly incomplete justification for the apparently discriminatory practice of licensing adoptive, but not biological, parents. If there is already a relationship between babies and bearing parents when babies are born, and this relationship is constitutive of adequate parenting, then there is less reason, other things being equal, to scrutinise both the parental entitlement and the parental adequacy of bearing parents than that of adoptive parents. Perhaps this claim is best understood if formulated in terms of parents' abilities. Having a baby is in some sense similar to inviting into your home, and taking responsibility for, a stranger. The 'visit' will last forever-or, at least, for two decades. The responsibility will be enormous, at least during the first few years. In spite of, and sometimes in virtue of, its tribulations, pregnancy may smooth the way-we have reasons to believe it helps prepare people for the dramatic change brought about by parenthood. Bearing parents have an advantage over adoptive parents in this respect. This, of course, does not mean that adoptive parents cannot make equally good parents-only that they have a different, and in a way more difficult, starting point. A charitable interpretation of the practice of licensing adoptive parents acknowledges this difference. (Though this difference, nonetheless, is likely to be insufficient as an overall justification for licensing adoptive, but not biological, parents.)

\footnotetext{
${ }^{47}$ See, for example: Sarah-Vaughan Brakman and Sally Scholz, 'Adoption, ART, and a re-conception of the maternal body: toward embodied maternity', Hypatia, 21 (2006), 54-73.

${ }^{48}$ Marilyn Friedman, personal communication, 10 July 2010.
} 
Fourth, the argument of this article may shed new light on dilemmas around the moral and legal rights of surrogate mothers. Sometimes women who have agreed to act as surrogate mothers for another couple become reluctant to, or outright oppose, giving away their babies after birth. If having borne a baby is a ground for a right to keep that baby, the important question for surrogacy is whether this right is alienable and under what conditions. Is it possible to wave one's right to keep one's birth baby before one knows exactly what burdens the pregnancy will entail, and what kind of relationship one will establish with the new born? In other words, can a surrogacy contract pre-empt the rights of the gestating mother or couple? I remain, in this article, agnostic about this.

Fifth, I cannot engage here with the question of whether the right to parent one's biological baby, grounded in the usual facts of pregnancy, is strong enough to exclude a redistribution of babies to other prospective parents when the birth parents already have many children and the prospective parents have none. My tentative answer is positive: the existence of an intimate connection to the baby at birth implies that forced separation would be an act of cruelty, irrespective of how many other children the birth parents have. It is true that, given a right to parent in general, there is unfairness in the fact that people who would make adequate parents remain childless through no fault of their own, while other people can have many children. But it is plausible that avoiding cruelty is more important than realising fairness towards the childless. However, upholding parents' right to keep all the children with whom they are already in a relationship does not, in itself, say much about the content of a legitimate parenting relationship. Contrary to prevalent practice and opinion, parents might not have the right to exclude all other adults from having close relationships with their children.

Finally, the scope of the present argument is limited to one right only: bearing parents' right to keep their babies. It is silent, for example, about the proper extent of the controversial parental right to shape one's child's personality, values or social life. It also does not imply anything about genetic connections: the argument gives equal support to the rights of parents whose pregnancies resulted from implementation of an embryo with a different genetic makeup. In spite of its limited scope, my argument provides reasons against legal practices which automatically settle custody disputes in favour of genetic parents over birth parents or, indeed, over social parents who have already developed intimate relationships with their children.

The parental right to keep one's birth baby obviously depends on the way in which we come into the world. If human procreation were to change radically, such that babies would no longer gestate and be born out of other human bodies, then a case for allocating babies to future parents via lotteries would become significantly stronger. Not only would the meaning of 'biological parent' become less substantial, and signify a genetic connection only, but such change would pose a radical challenge to parents' right to keep their biological babies. 
This points to the unavoidable relevance of empirical facts when thinking about the justice of having and raising children. I argued that the plausibility of fundamental parental rights relies on assumptions about facts, which are true about the world as we know it. Some of these facts are indeed very likely to remain unchanged, such as those, discussed by Brighouse and Swift, about the special relationship between parents and children, or those about the gradual nature of what we consider good parenting, and about the epistemic and moral difficulties in establishing degrees of parental competence. We do not know how to change these facts. Furthermore, they seem to be very deeply connected with what it means to be a human being, so it is not obvious that we should ever try to change them. Other facts, like gestation, are more likely to change-whether such change would be desirable or not. All these facts are paramount for understanding parents' and children's interest-based rights, and hence it is important to keep them in the foreground of normative discussions concerning parenthood. 